\title{
$\cos f-930926--30$
}

UCRL- JC-115217

PREPRINT

The Superconducting Solenoid Magnet System for the GEM Detector at the SSC

G. Deis, J. Bowers, A. Chargin, J. Heim

A. House, C. Johnson, G. Oberst, L. Pedrotti,

J. Swan, R. Warren, S. Wineman, R. Yamamoto,

R. Camille, G. East, P. Marston, J. Minervini,

R. Myatt, S. Myatt, R. Pillsbury, J. Pace, Z. Piek,

A. Sidi-Yekhlef, B. Smith, J. Sullivan, P. Titus,

J. Krupczak, N. Martovetsky, P. Reardon, R. Richardson,

D. Richied, R. Stroynowski, J. Bohanan, J. Gertsen,

J. Heck, N. Howe11, M. Wilson, B. King, S. Robinson,

J. Rollins, R. Vieira

This paper was prepared for submittal to the 13th International Conference on Magnet Technology

Victoria, Canada September 20-24, 1993

September 8, 1993

This is a preprint of a paper intended for publication in a journal or proceedings. Since changes may be made before publication, this preprint is made available with the understanding that it will not be cited or reproduced without the permission of the author.



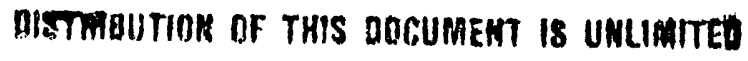




\section{DISCIAIMER}

This document was prepared as an accoual of work sponsored by an apency of the United States Government. Neither the Uniled Stales Coverameat nor the University: of Californiz nor any of their employees, makes any warrani i̦ express er implied, or assurnes any legal liability or responsibility for the accuractic compteteness, or usefulmess of any informalion, apparalus, produch or process disctosed, er represents that its use would aor infringe privately owned rights. Refereace herein to any sperific commercial produrts, processis, or service by trade narme. tradementh manufacturer, or otherwise, does aot aecessarily constitute or imply its endersemear, mecoenencendation. or favoring by the Uniled Stales Governmeat or the University of California. The viens and opinions of authors expressed herein do not necessarily state or reffert those of the Uniled Sutes Government or the University of California and shall nor be used for advertising or product endorsemem porposes. 


\section{The Superconducting Solenoid Magnet System for the GEM Detector at the SSC}

G. Deis, J. Bowers, A. Chargin, J. Heim, A. House, C. Johnson, G. Oberst,

L. Pedrotti, J. Swan, R. Warren, S. Wineman, R. Yamamoto

Lawrence Livermore National Laboratory ${ }^{\dagger}$

P.O. Box 808, Livermore, CA 94550

R. Camille, G. East, P. Marston, J. Minervini, R. Myath, S. Myatt,

R. Pillsbury, Z. Piek, B. Smith, J. Sullivan, P. Titus, R. Vieira

Massachusetts Institute of Technology, Plasma Fusion Center

185 Albany Street, Cambridge, MA 02139

J. Krupczak, N. Martovetsky, J. Pace, P. Reardon, R. Richardson, D. Richied, A. Sidi-Yekhlef, M. Wilson

Superconducting Super Collider Laboratory $\ddagger$

2550 Beckleymeade Ave., Dallas, TX 75237

R. Stroynowski

Southern Methodist University, Dallas, TX

J. Bohanan, J. Gertsen, J. Heck, N. Howell, B. King, S. Robinson, J. Rollins

DOE Y-12 Plant $\$$

Oak Ridge, TN

\begin{abstract}
The design of the magnet for the GEM detector at the SSC is described. It is an $18 \mathrm{~m}$ inner diameter, $30 \mathrm{~m}$ long superconducting solenold, with a magnetic field of $0.8 \mathrm{~T}$. The basic solenoidal fleld is shaped by large ferromagnetlc cones, to improve detector performance in the ends of the solenoid. Because of the system's large size and mass, fleld-fabrication on-site at SSC is required. The challenges in this process, together with the large stored energy of the system, $2.5 \mathrm{GJ}$, have lead to novel design choices In several areas, including the conductor. The design of the conductor, cold mass, vacuum vessel, cold mass supports, thermal shields, forward field shapers, and auxillary systems are described.
\end{abstract}

\section{INTRODUCTION}

When the Superconducting Supercollider begins producing the high-energy proton collisions for which it is designed, two "large" detectors will be used to perform the physics experiments. The GEM detector is optimized for the precise measurement of high-energy photons, electrons, and muons. Particle identification and tracking in GEM relies on

\footnotetext{
* Manuscript submitted 20 September, 1993

† Work performed by LLNL, for the US. Department of Energy under Contract No. W-7405-ENG-48.

‡ Operated by the Universities Research Association, Inc., for the US. Department of Energy under Contract No. DE-AC35-89ER40486.

$\S$ Operated by Martin Marietta Energy Systems, Inc., for the US. Department of Energy under Contract No. DE-AC05-84OR21400
}

a magnetic field to bend the trajectories of charged particles. The magnetic field is produced by a large superconducting solenoid, which surrounds all the detector subsystems, and provides a large volume through which particles are tracked over relatively long distances. Although the magnetic field is modest by superconducting magnet standards, the large size and stored energy of the system present a unique set of challenges. The preliminary design for this magnet subsystem has been developed over the past two years, by a team consisting of the SSC Laboratory, Lawrence Livermore National Laboratory, the Massachusetts Institute of Technology Plasma Fusion Center, and the DOE Y-12 Plant at Oak Ridge, in consultation with numerous industrial representatives.

\section{DESIGN OVERVIEW}

A basic philosophy of the GEM Detector is to provide a large magnetized volume, in which the major detector subsystems are installed [1]. The resolution of particle momentum measurement increases linearly with the magnetic induction, and quadratically with the radial dimension of the magnet. Through parametric studies, we found that the overall cost, construction time, and most other considerations favored the choice of a simple superconducting solenoid without ferromagnetic flux return, over a resistivemagnet approach. We found that the optimum choice for our application is a solenoid with $18 \mathrm{~m}$ inner diameter, $0.8 \mathrm{~T}$ central field, and $31 \mathrm{~m}$ overall length. Large ferromagnetic "Forward Field Shapers" are used to shape the magnetic field for improved detector performance near the ends of the solenoid. These design choices have the further advantages of 


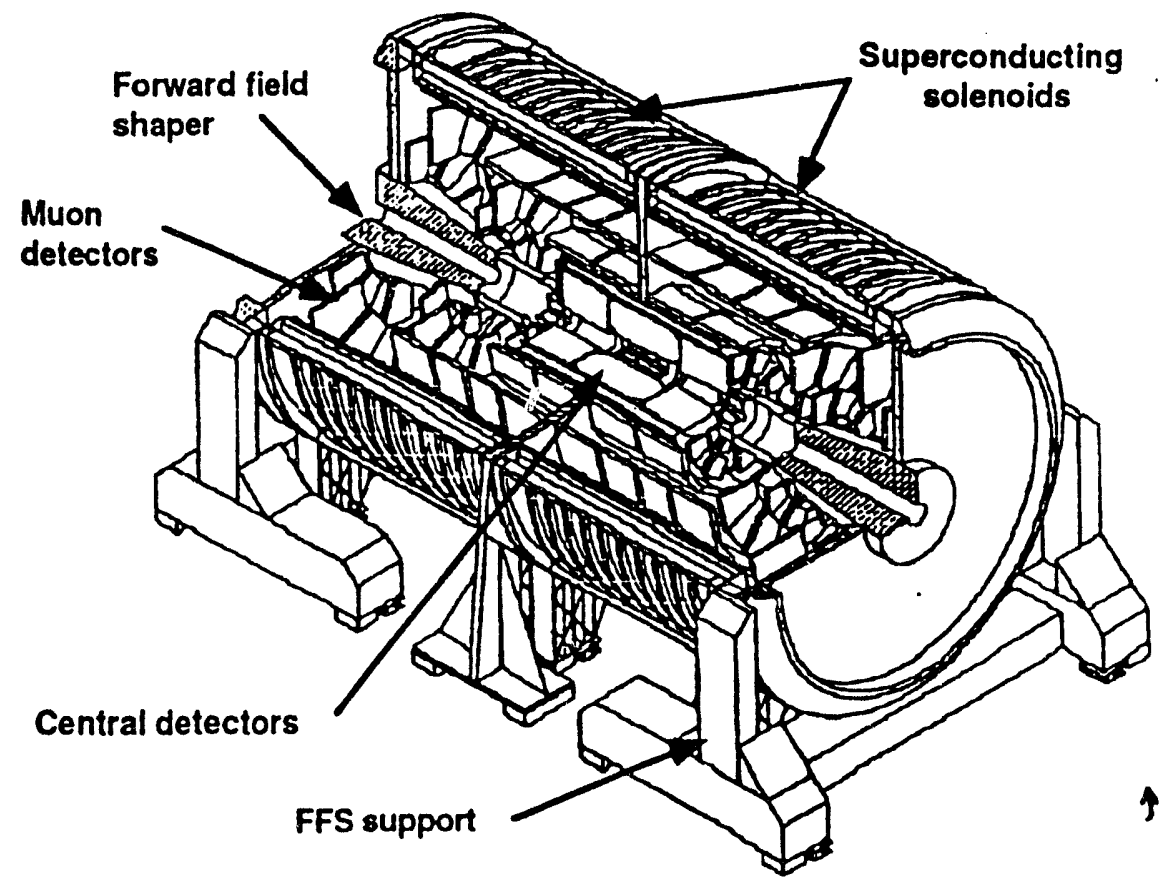

Fig. 1 - GEM Detcctor

fitting into an underground ball of reasonable size, and allowing a simple and low-risk single-layer winding design.

The present GEM detector design is shown in Fig. 1. The magnet subsystem comprises the four main parts on the outside: two separate superconducting solenoids, and the two conical Forward Field Shapers which occupy the ends of the solenoids. Also included in the subsystem, but not shown in Fig. 1, are the auxiliary systems, vacuum, cryogenics, power/protection, and control, which are required for operation of the magnet. Basic system parameters are listed in Table 1.

The overall design concept for the GEM magnet requires that much of the fabrication and all of the final assembly must take place on-site at the SSC Laboratory. These factors have also played an important role in defining the design details, which must be compatible with and mitigate the inherent difficulties of field-fabrication. This has lead to design choices which differ from previous large detector magnets.

\section{CONDUCTOR}

We initially considered a variety of different conductor types, but quickly narrowed the choices to cable-in-conduit (CIC) and indirectly-cooled (IC) conductors. Two point-design studies were completed to evaluate and compare these designs. While the IC concept, in which a conductor is bonded onto a cooled coil form, could fulfill the technical requirements, it would require exceptional accuracy in the production of the coil form, the winding of the conductor, and the bonding of the conductor to the form; flaws in these operations would also be difficult to detect. The $\mathrm{CIC}$ conceph having a much larger energy stability margin, would be more tolerant of such imperfections, but would entail risks in splices between lengths of conductor, in the integrity of the conductor itself, and in quench protection. These risks, bowever, are all subject to testing and verification, leading to lower overall technical risk. R\&D and design efforts have already produced a high-quality splice design [5], and have begun developing QA methods for conductor production; a full-scale conductor performance verification test in now in construction.

The conductor design is shown in Fig. 2, and the key parameters are summarized in Table 2 [2], [3]. At the center

\begin{tabular}{lll} 
TABLE 1 - GEM MAGNET SYSTEM PARAMETERS \\
\hline Central induction & 0.8 & $\mathrm{~T}$ \\
Mean winding radius & 9.5 & $\mathrm{~m}$ \\
Vessel inner diameter & 18.0 & $\mathrm{~m}$ \\
Vessel outer diameter & 21.8 & $\mathrm{~m}$ \\
Overall coil length & 31.0 & $\mathrm{~m}$ \\
Number of turns & 456 & \\
Operating current & 50.2 & $\mathrm{kA}$ \\
lnductance & 1.98 & $\mathrm{H}$ \\
Stored energy & 2.5 & $\mathrm{G}$ \\
Peak field al conductor & 1.6 & $\mathrm{~T}$ \\
Operating temperature & 4.5 & $\mathrm{~K}$ \\
Total conductor length & 27.2 & $\mathrm{~km}$ \\
Charging time & 8 & $\mathrm{hr}$ \\
Total cold mass & 1050 & $\mathrm{Mg}$ \\
Total coil ass' y mass & 1500 & $\mathrm{Mg}$ \\
Mass of FFS + support & 2000 & $\mathrm{Mg}$ \\
\hline \hline
\end{tabular}




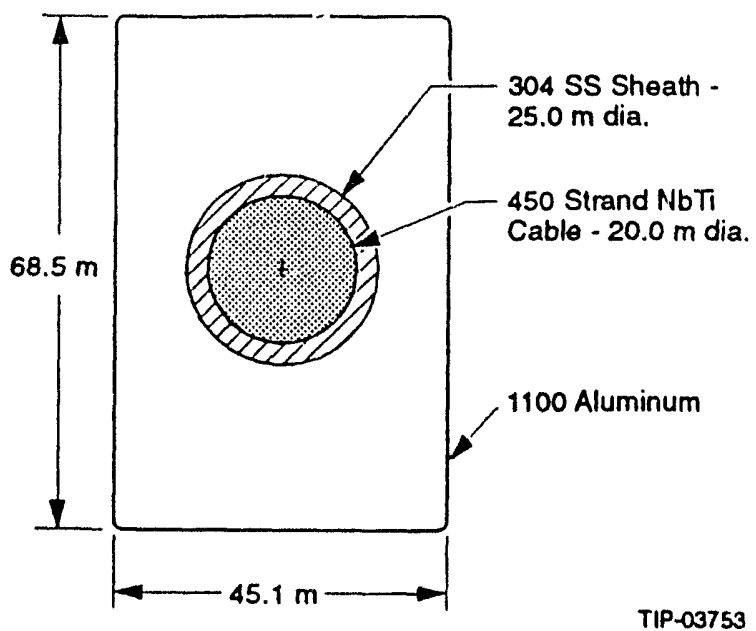

Fig. 2 GEM magnet conductor cross-section

is superconducting cable with 450 strands of multifilamentary NbTi in a copper matrix. This cable is enclosed in a 304 stainless steel tube. In operation, this conduit is filled with supercritical helium at $4.5 \mathrm{~K}$, which provides the large transient stability margin. This cable-inconduit is then enclosed in an aluminum "sheath," which is designed to carry the current during a quench, providing hotspot protection for the superconductor [4].

\section{COLD MASS}

Each of the two cold mass halves is $19 \mathrm{~m}$ diameter, $14.5 \mathrm{~m}$ long, and weighs 525 metric tons. The large size and weight dictates a modular design for winding, so we chose to construct each cold mass half out of 12 coil modules. Each module (Fig. 3) contains one continuous length of conductor, $1.2 \mathrm{~km}$ long. The conductor is wound in a 19-tum single layer coil onto the inside of a cylindrical aluminum coil form, $76 \mathrm{~mm}$ thick, which provides mechanical support and cooling. The coil form is made up of bolted quadrants, which are electrically isolated to reduce eddy-current beating during transients. The coil form includes flanges at each end, which accept axial magnetic forces, and provide a compressive preload which minimizes axial conductor motion resulting from magnetic force.

\begin{tabular}{lll} 
TABLE 2 - CONDUCTOR AND COLD MASS PARAMETERS \\
\hline \hline Strand diameter & 0.73 & $\mathrm{~mm}$ \\
Cu:Sc ratio & $3.6: 1$ & \\
Copper RRR & $>150$ & \\
Number of strands & 450 & \\
304L conduit ID/OD & $20 / 25$ & $\mathrm{~mm}$ \\
Cable space void fraction & $37 \%$ & \\
Al sheath dimensions & $49.8 \times 68.5$ & $\mathrm{~mm}$ \\
Number of turns per module & 19 & \\
Mean widing diameter & 9.5 & $\mathrm{~m}$ \\
overall module length & 1.2 & $\mathrm{~m}$ \\
conductor length per module & 1134 & $\mathrm{~m}$ \\
Operating temperature & 4.5 & $\mathrm{~K}$ \\
\hline \hline
\end{tabular}

The twelve coil modules are wound individually, and are then stacked, with axis vertical, to produce a cold mass half. The modules are connected mechanically by bolting the flanges together. The conductor is spliced electrically with low-resistance, large-area lap-type joints [5].

\section{VACUUM VESSEL}

Insulating vacuum and physical support are provided separately for the two cold mass halves, by two annular steel vacuum vessels. Each vessel is approximately $22 \mathrm{~m} \mathrm{OD,} 15$ m long, and weighs 900 metric tons, and is made up of four basic parts: a membrane-like, $25 \mathrm{~mm}$ thick inner shell, a 25 mm thick outer shell with external stiffeners to resist the atmospheric pressure, and two $75 \mathrm{~mm}$ thick annular end rings. The end rings connect the two shells, provide stiffness for the entire system, and provide attachment points for legs and cold mass supports. In addition to the vacuum load and their own weight, the vessels must support the weight of the cold mass and the net magnetic force on the cold mass and FFS. The axial stiffeners on the outer vessel are designed primarily to resist these axial magnetic forces. The vessels are made up of stainless steel and low-carbon steel, to meet the combination of magnetic and cryogenic performance requirements at minimum cost. They will be fabricated on site, using standard techniques for large vessel cunstruction, by welding together factory-fabricated sections, each of size compatible with over-the-road shipping [6].

\section{COLD-MASS SUPPORTS AND THERMAL SHIELDS}

During operation, the cold mass halves are supported against gravity as well as an attractive magnetic force of $52 \mathrm{MN}$ by two sets of titanium rods. At each end of each cold mass half, 8 opposed pairs of tangentially-oriented rods support the cold mass against radial forces, primarily the weight. These rods are oriented so that they allow the radial contraction of the cold mass at cooldown, and expansion of the cold mass due to magnetic forces at charging, but support its weight and maintain its roundness. They connect to reinforced areas on the end flanges of the outer modules of each cold mass half, and to reinforced locations on the vacuum vessel end rings. The axial forces on each cold mass half are born on eight long titanium "flexures," which connect to the cold mass at the middle, and to the vacuum vessel outer end ring. The slenderness of these elements allows them to flex to accommodate radial motion of the cold mass, during cooldown and charging. All of these rods are made of titanium alloy, and each is thermally connected to the thermal shields, to minimize the heat leak to the $4.5 \mathrm{~K}$ cold mass.

The cold mass is completely enclosed in LNcooledthermal radiation shields. Each of the 32 shields per magnet half is made up of aluminum sheets with welded-on 




Fig. 3 Coil module cross-section.

stiffeners. An extruded aluminum cooling tube is also welded on each, and the panel is surrounded on both sides by multilayer insulation, which reduces both the consumption of LN and the heat load to the cold mass.

\section{FORWARD FIELD SHAPERS}

The FFS's provide the desired shape in the otherwisesolenoidal field. They must be supported against gravity and magnetic loads, without intruding significantly on the interior of the detector, as shown in Fig. 1. Each FFS is assembled by stacking up interlocking disks of low-carbon steel, with axis vertical. When the stack is complete, the disks are held together with pre-tensioned members which extend through the stack. The interlocking features between the disks support the large shear forces from the cantilevered support. The FFS support structures are large plate-type weldments, to which the FFS's are bolted. The support structures are fabricated in roughly ten large sections, which are shipped to the SSCL site and bolted and welded together.

\section{AUXILIARY SYSTEMS}

Given the extremely stable conductor and conservative cold mass design, the availability of the auxiliary systems will determine the overall system availability. We have taken the approach of designing them to ensure continuous operation, even during fault conditions such as electrical power or refrigerator outages.

The cooling for the cold mass is a passive thermosyphon design, which relies on stored liquid helium. It circulates at roughly atmospheric pressure and $4.5 \mathrm{~K}$ through tubes on the outside of the coil forms to remove radiated and conducted heat to the cold mass. Supercritical helium $(3 \mathrm{~atm}, 4.5 \mathrm{~K})$ is supplied separately at low flow rate to the conductor conduit, but this flow is not intended to remove significant heat. Overall, we require approximately $2 \mathrm{~kW}$ refrigeration, plus $20 \mathrm{~g} / \mathrm{s}$ liquefaction. With the passive thermosyphon design for heat removal, and only stored LHe, the magnet system is designed to operate for up to eight hours without the refrigerator, which should allow sufficient time for repair of most of the likely refrigerator faults.

The power and protection system is designed to accomplish a normal charge or discharge in $\mathbf{8}$ bours, and is capable of an emergency discharge in 5 minutes. It includes the main $50 \mathrm{kA}, 20 \mathrm{~V}$ DC power supply, which is connected to the magnet with forced-air cooled aluminum busses. A dump resistor and redundant circuit interrupters are included in the circuit to provide for the fast emergency discharge. Finally, sensors and controls are provided to constantly monitor the condition of the magnet, and control all systems simultaneously.

\section{SUMMARY}

The GEM Magnet will be one of the largest superconducting magnets ever built. The design challenges for this magnet derive more from the large size, weight, and stored energy, and from the rigors of field-fabrication, than from the more typical difficulties of superconducting magnet design. We have addressed these challenges at all levels, from the selection of an extremely stable superconductor concept, to the design of the auxiliary systems for robust, highavailability operation.

\section{REFERENCES}

(1) B. Barish, et.el, "GEM Technical Design Report," SSCL report no. GEM-TN-93-262, April, 1993.

[2] N. Martovetsky, at. al., Conductor Design for the GEM Magnet, Supercollider SIIISSC Proceedings, in press.

[3] B. Smith, et.al., Design Concept for the GEM Detector Magnet, Applied Superconductivity Conference, Chicago, Ill., 1992.

[4] E. Chaniotakis, A. Radovinski, "Thermo-Hydraulic Design Analysis of the GEM Detector Magnet System," IEEE Trans. Mag., in press.

[5] B. Smith, et.al., "Electrical Joints Between Superconducting Coil Modules in the GEM detector Magnet," IEEE Trans. Mag., in press.

[6] L. Pedrotii, et. al., "Plans for Building the Largest Thin Solenoid Ever,"IEEE Trans. Mag., in press.

[7] R. Warren, et al., "A Liquid Helium Cryogenic System Design fot the GEM Magnet," Proc. ICEC/ICMC, in press. 

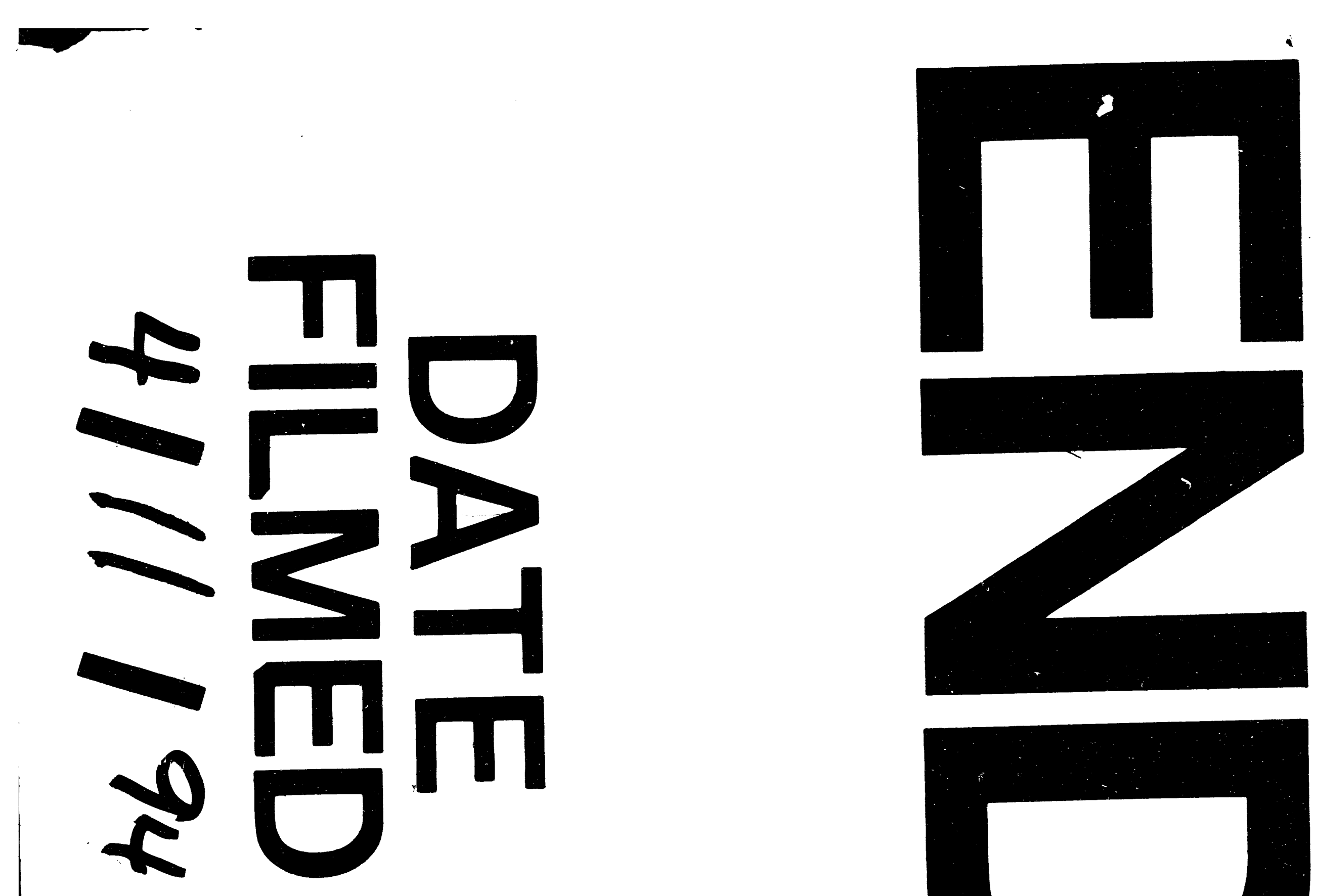

1
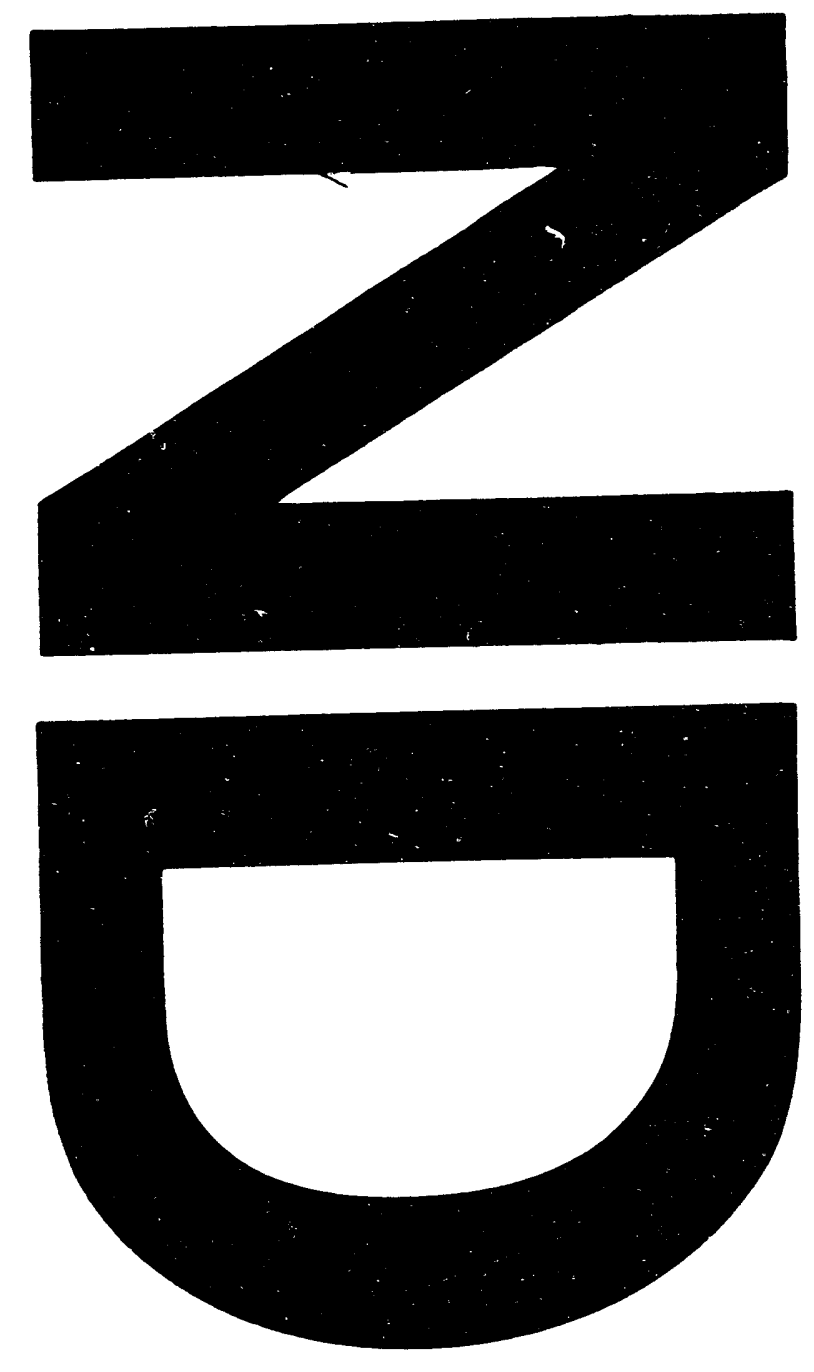

1 
